\title{
Evolution of isokinetic strength and return to sport after proximal hamstring rupture without surgical repair: a retrospective series of cases.
}

\author{
A. Fouasson-Chailloux 1, 2, 3, P. Menu'1, 2, 3, O. Mesland ${ }^{1,2}$, Y. Guillodo4, \\ V. Crenn ${ }^{5}$, M. Dauty ${ }^{1,2,3}$ \\ 1 CHU Nantes, Physical Medicine and Rehabilitation department, Hôpital Saint Jacques, 85 rue Saint Jacques, \\ 44093 Nantes cedex 03. France \\ 2 CHU Nantes, Sports Medicine department, Hôpital Saint Jacques, 85 rue Saint Jacques, 44093 Nantes cedex \\ 03. France \\ 3 Inserm, UMR 1229, RMeS, Regenerative Medicine and Skeleton, Université de Nantes, ONIRIS, Nantes, \\ F-44042, France \\ 4 CHU Brest, Rheumatologic Department, University Hospital of Brest, Brest, France \\ ${ }_{5}$ CCOT, Orthopaedic surgery department, CHU de Nantes, 1, place Alexis-Ricordeau, 44093 Nantes cedex 1, \\ France
}

\author{
CORRESPONDING AUTHOR: \\ Alban Fouasson-Chailloux \\ MPR Locomotrice et Respiratoire \\ $\mathrm{CHU}$ de Nantes, Hôpital St Jacques, \\ 85 rue Saint Jacques, \\ 44093 Nantes, Cedex 1. \\ E-mail: \\ alban.fouassonchailloux@chu-nantes.fr \\ Phone: +33240 846211
}

DOI:

10.32098/mltj.02.2019.03

LEVEL OF EVIDENCE:

4

\begin{abstract}
SUMMARY
Introduction. Proximal ruptures of hamstrings are rare. Their evolution in absence of surgery is relatively unknown. We aimed to describe the evolution of patients with non-operated proximal hamstring ruptures, in terms of strength recovery, self-satisfaction and return to sport. Methods. We included retrospectively 16 patients addressed for isokinetic strength evaluation of the hamstrings after non-operated unilateral proximal rupture. Isokinetic strength assessment was performed between 4 and 100 months after injury and subjective scores were performed at the last follow-up. The concentric evaluation was performed with 3 repetitions at $60 \%$ s followed by 5 repetitions at $180 \%$ s. The eccentric mode was evaluated by 5 repetitions at $60 \%$ followed by 5 repetitions at $120 \%$ s. Results. All the patients went back to sport, with a mean time of $7.0+/-2.9$ months, to the same level of practice or to a lower level. The Tegner score was decreased from $6.9+/-1.7$ to $6.1+/-1.9(\mathrm{p}=0.03)$. Fifteen patients were very satisfied or satisfied and subjective scores were high. Four months after the injury, the concentric strength deficit was $40 \%+/-25$ and decrease to $25 \%+/-12$ at 2 years. Yet, eccentric deficit persisted in time. Conclusion. Subjective results were good despite a persistence of an isokinetic strength deficit.
\end{abstract}

\section{KEY WORDS}

Muscle; Hamstring; Isokinetic; Eccentric; Sport; Non-operative.

\section{INTRODUCTION}

Hamstring injuries are well described because of their frequency in high-level athletes $(1,2)$. They represent 12 to $24 \%$ of the lesions during a sport-season in professional soccer players $(3,4)$. However, proximal lesions are not very frequent, about $12 \%$ of whole hamstring lesions (5). According to the micro-traumatic or traumatic mechanism, 3 entities may be schematically identified: tendinopathy, incomplete rupture (depending on the numbers of injured tendons) and complete rupture of the 3 muscle insertions, that is to say, semitendinosus, biceps femoris and semimembranosus (6-8). Many asymptomatic cases have been reported in case of degenerative tendons (9). In getting older, $2 \%$ of the general population, has an asymptomatic bilateral complete rupture and $15 \%$ an asymptomatic bilateral incomplete one. Semimembranosus insertion is usually the 
most often injured. Most of the cases described in literature are from surgical series. Yet, surgery remains controversial because of the absence of randomized prospective study $(10,11)$. Traumatic complete rupture of the hamstrings with a retraction of more than 2 centimeters, diagnosed in the first 4 weeks in young athletes seems to be the best surgical indications $(2,10,12-15)$. Complications after surgery may occur, such as rupture recidivism (2.1 to $2.8 \%$ ) and superficial infections $(2.4$ to $3.25 \%)(10,11)$. Residual pain is reported in 8 to $61 \%$ of the cases and $71 \%$ of the patients have a lack of confidence in their operated leg (16). Anyway, Van der Made et al. found that $76 \%$ of the subjects returned to the same sport but only $55 \%$ to the same sport level. Conversely, only few non-operated cases have been reported $^{10}$. In their systematic literature review, Harris et al. found only 14 non-operated cases that they compared to 284 operated case (11). More recently, Bodendorfer et al. described only 28 non-operated cases from 795 cases of proximal hamstring avulsions (10). The first series reporting 10 non-operated cases, were published in 1996(17). Results were not good in terms of return to sport but, it concerned only water-skiers. Water-skiing is the principal sport providing such lesions and return to sport remains difficult whatever the treatment $(11,18)$. Hofmann et al.(19) and Shambaugh et al.(20) reported respectively 17 and 14 new cases of non-operated complete hamstring avulsions but without specific details on sport practice. As hamstring proximal rupture is considered to be at the origin of disabling pain preventing return to sport, preferring surgical approach has been justified despite its several limits $(10,11)$. Yet, some reported cases show the possibility to go back to sport without surgical repair $(21,22)$. Other authors described non-surgical management based on anti-inflammatory drug intake associated with hip range of motion recovery $(2,13,23)$. Ultrasound and shock wave therapies are proposed in case of persistent pain. In third intention, corticosteroid or platelet rich plasma injections may be proposed (24). In case of failure of these medical therapeutics, surgery remains possible $(13,14)$. Given the lack of knowledge about non-operated proximal ruptures of the hamstrings, the aim of this study was to described the evolution of a series of patients with non-operated hamstring injuries, especially in terms of strength recovery, self-satisfaction and return to sport.

\section{MATERIALS AND METHODS}

\section{Patient selection}

We retrospectively included all the patients addressed for at least one isokinetic strength evaluation of the hamstrings after non-operated unilateral proximal rupture of the hamstrings between 2004 and 2014. Rupture was confirmed by MRI imaging and classified according to ISMuLT Guidelines for muscle injuries (25). This type of recruitment did not influence the initial management of the lesions. Criteria of inclusion were: complete proximal ruptures of at least one tendon of the hamstrings at the proximal level; age over 18; injuries during sport practice. Criteria of exclusion were: surgical management of the hamstring rupture; distal rupture of the tendons; bone avulsion of the proximal hamstring origin.

\section{Isokinetic evaluation}

Muscular strength evaluation was performed with an isokinetic dynamometer (Cybex Norm ${ }^{\circledR}$ Lumex Inc. Ronkonkoma, NY, USA) according to a standardized procedure (26): 10 minute warm-up on bicycle, conditioning with the machine (realization of 5 submaximal movements and 2 maximal) and then performing the isokinetic test starting with the non-injured side. Isokinetic concentric strength of the hamstrings was performed for each patient, associated to eccentric measures, which are close to traumatic mechanisms $(17,27)$. The concentric evaluation was performed with 3 repetitions at $60^{\circ} \mathrm{s}$ of angular speed followed by 5 repetitions at $180^{\circ} \%$. The eccentric mode was evaluated by 5 repetitions at $60 \%$ s of angular speed followed by 5 repetitions at $120 \%$ s. Verbal encouragements were provided during the tests, and 30 seconds of recovery were given between each series. Dynamometer calibration was monthly performed according to the constructor recommendations. Knee flexors peak torques (hamstrings) was measured and gravity corrected, allowing to calculate strength deficit compared to the healthy side with the formula: 1- (Knee flexors peak torques of the injured side / Knee flexors peak torques of the healthy side). Moderate relative reliability of 0.85 was established for strength ratio by intraclass correlation coefficient (28).

\section{Individual evaluation}

Patients' interviews at the end of the follow-up permitted to evaluate the level of sport practice compared to those before muscular rupture with Tegner score (29). Delay to return back to sport was determined from the date of the traumatism. Physical activity level and pain persistence were measured with the University of California at Los Angeles Activity Scale (UCLA) from 1 to 10 (30). Function was measured with the Lower Extremity Functional Scale (LEFS) from 0 to 80 with a minimal detectable change of 9 points (31). Individual satisfaction was evaluated by choosing a term between very satisfied, satisfied, moderately satisfied and unsatisfied (32).

Muscles, Ligaments and Tendons Journal 2019;9 (2) 


\section{Statistical analysis}

Statistical analyses were performed with SPPS 23.0 software (IBM corp. Dublin, Ireland). Quantitative variables were given in mean, median and standard-deviation. Comparison of the Tegner score before and after hamstring rupture was made with a Wilcoxon non-parametric test. Comparison according to incomplete (1 or 2 muscular insertions) or complete rupture ( 3 insertions) was performed with a $\mathrm{U}$ test of Mann-Whitney. Results were considered significant for $\mathrm{p}<0.05$.

\section{Ethics}

Applicable institutional and governmental regulations concerning ethics were followed during this research. The data report form was declared to the French data protection authority (Commission Nationale de l'Informatique et des Libertés) and to the Research Department of the University Hospital under the registration number RC18_0024. Since data were collected retrospectively and that patients' management was not modified, according to French law, this study did not need to be approved by a research ethics committee (articles L.1121-1 paragraph 1 and R1121-2, Public Health code). This study followed the basic principles and recommendations in clinical and field science research (33).

\section{RESULTS}

Sixteen patients were included, 10 men and 6 women. The mean follow-up was 73 months +/- 39 (24-144). Patient mean age at the time of the rupture was 34 years +/- 12 (18-49). All the subjects were interviewed. Six patients had a complete proximal rupture of the 3 tendons. Out of the 10 other patients, 5 had a rupture of two muscle insertions, 5 had a unique proximal rupture (Table I). Tendon retraction was superior to 2 centimeters in 14 cases $(4.0 \mathrm{~cm}+/-1.6$ $(1.0-7.0))$. All these injuries were type IV of the ISMuLT classification (25). Clinical diagnosis of proximal hamstring rupture was made 4.0 months +/- $1.7(2.0$ - 6.0) after traumatism. Fourteen patients reported an ecchymosis. Surgery had never been proposed.

Ten patients out of 16 were very satisfied and 5 out of 16 were satisfied with the evolution of their injury at the time of the clinical interview (Table I). The mean time to go back to sport was 7.0 months $+/-2.9(4.0-12.0)$. All the patients were able to practice sport but 4 of them could not run again. Yet, these 4 patients were satisfied with regular practice of cycling. Conversely, 6 patients went back to sport and to their previous levels, and 4 changed sports but for an equivalent one (Table II). Before hamstring injury, the Tegner score was $6.9+/-1.7(5-10)$ and after, at the time of follow-up, the score significantly decreased at $6.1+/-1.9$ (4

Table I. Details of the history of the 16 patients

\begin{tabular}{|c|c|c|c|c|c|c|c|c|}
\hline $\mathbf{N}^{\circ}$ & Sex & $\begin{array}{l}\text { Age } \\
\text { (years) }\end{array}$ & Type of rupture & $\begin{array}{l}\text { Muscle } \\
\text { defect }(\mathrm{cm})\end{array}$ & Side & Sport & $\begin{array}{l}\text { RTS time } \\
\text { (month) }\end{array}$ & Satisfaction \\
\hline 1 & $\mathrm{~F}$ & 45 & $1 / 2 \mathrm{~T}+1 / 2 \mathrm{M}$ & 4 & $\mathrm{R}$ & Water skiing & 12 & Very satisfied \\
\hline 2 & $\mathrm{~F}$ & 49 & $1 / 2 \mathrm{~T}$ & 6 & $\mathrm{R}$ & Sport teacher & 4 & Satisfied \\
\hline 3 & $\mathrm{M}$ & 22 & $1 / 2 \mathrm{~T}$ & 1 & $\mathrm{R}$ & Soccer & 4 & Very satisfied \\
\hline 4 & $\mathrm{M}$ & 18 & $1 / 2 \mathrm{~T}+\mathrm{B}$ & 3 & $\mathrm{R}$ & Soccer & 10 & Very satisfied \\
\hline 5 & $\mathrm{M}$ & 49 & $1 / 2 \mathrm{M}+\mathrm{B}+1 / 2 \mathrm{~T}$ & 4 & $\mathrm{~L}$ & Marathon & 6 & Very satisfied \\
\hline 6 & $\mathrm{~F}$ & 20 & $1 / 2 \mathrm{~T}+\mathrm{B}$ & 4 & $\mathrm{~L}$ & Soccer & 10 & Very satisfied \\
\hline 7 & $\mathrm{~F}$ & 20 & $1 / 2 \mathrm{M}+\mathrm{B}+1 / 2 \mathrm{~T}$ & 5 & $\mathrm{R}$ & Handball & 6 & Satisfied \\
\hline 8 & $\mathrm{~F}$ & 24 & $1 / 2 \mathrm{M}+\mathrm{B}+1 / 2 \mathrm{~T}$ & 7 & $\mathrm{~L}$ & Basketball & 4 & Satisfied \\
\hline 9 & $\mathrm{M}$ & 32 & $1 / 2 \mathrm{M}+\mathrm{B}+1 / 2 \mathrm{~T}$ & 4 & $\mathrm{R}$ & Soccer & 7 & Satisfied \\
\hline 10 & $\mathrm{~F}$ & 38 & $1 / 2 \mathrm{~T}$ & 5 & $\mathrm{~L}$ & Water skiing & 10 & Satisfied \\
\hline 11 & $\mathrm{M}$ & 49 & $1 / 2 \mathrm{M}$ & 4 & $\mathrm{R}$ & Marathon & 12 & Moderately \\
\hline 12 & $\mathrm{M}$ & 48 & $1 / 2 \mathrm{~T}+\mathrm{B}$ & 5 & $\mathrm{R}$ & Marathon & 6 & Very satisfied \\
\hline 13 & $\mathrm{M}$ & 35 & $1 / 2 \mathrm{M}+\mathrm{B}+1 / 2 \mathrm{~T}$ & 5 & $\mathrm{~L}$ & Boxing & 10 & Very satisfied \\
\hline 14 & $\mathrm{M}$ & 20 & $1 / 2 \mathrm{M}+\mathrm{B}+1 / 2 \mathrm{~T}$ & 3 & $\mathrm{R}$ & Soccer & 10 & Very satisfied \\
\hline 15 & $\mathrm{M}$ & 32 & $1 / 2 \mathrm{~T}+\mathrm{B}$ & 1 & $\mathrm{~L}$ & Soccer PRO & 6 & Very satisfied \\
\hline 16 & $\mathrm{M}$ & 45 & $1 / 2 \mathrm{M}$ & 3 & $\mathrm{~L}$ & Water skiing & 12 & Very satisfied \\
\hline
\end{tabular}

Abbreviations: M: Male; F: Female; 1/2M: semi-membranosus; B:Biceps femoris (long head); 1/2T: semitendinosus: RTS: return to sport; R: right side; L: left side. 
Table II. Pre-injury (left column) and post-injury (right column) sport and level of Discussion

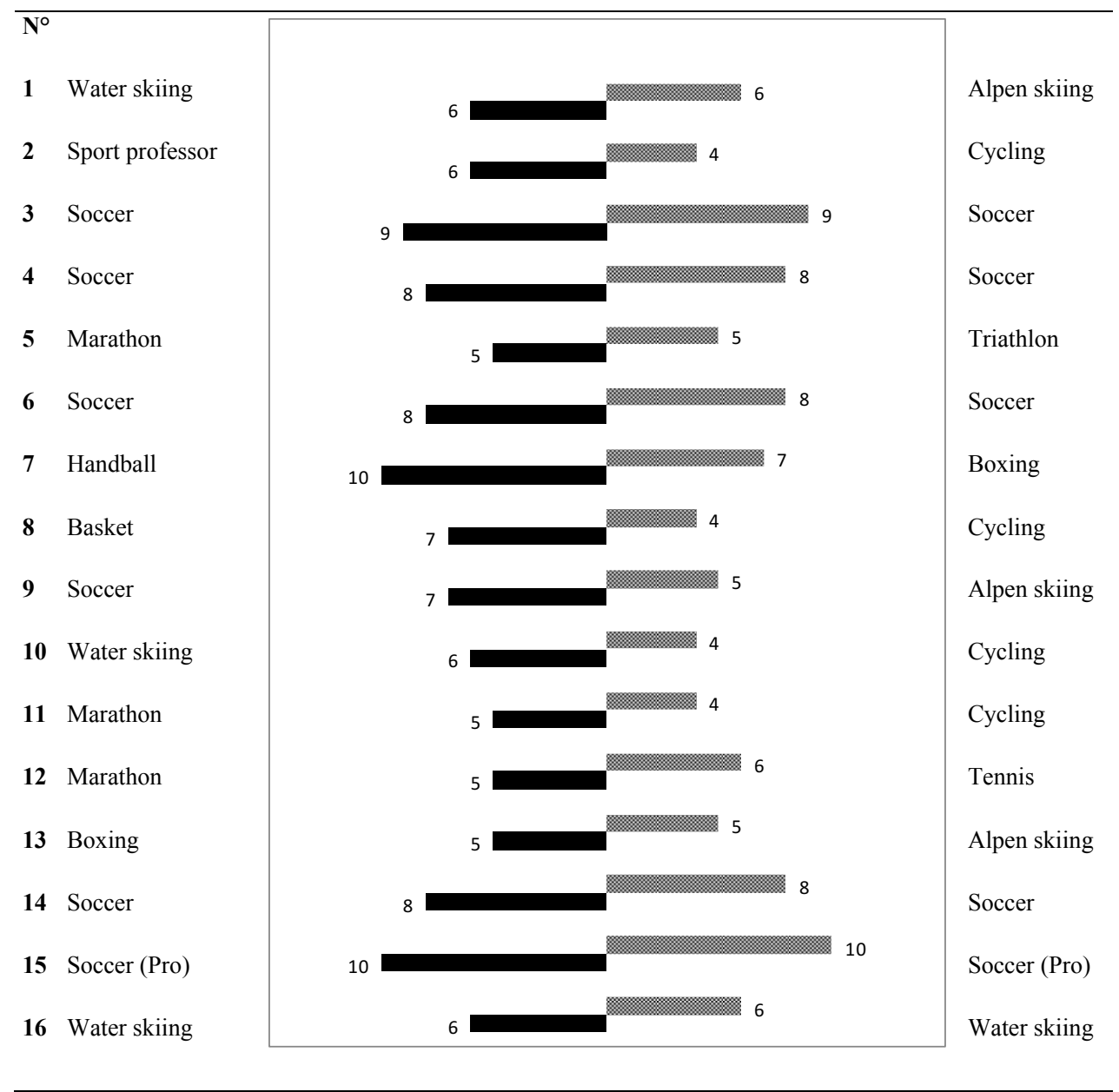

- 10) $(\mathrm{p}=0.03)$. No difference was found between patients with a complete rupture of the 3 tendons and those with a rupture of 1 or 2 tendons, concerning time to return to sport and the level of practice.

Fourteen patients had a LEFS superior to 71 and the mean score was 76.6 +/- 3.9. The UCLA mean score was $37.5+/$ 2.2 points, with $8.7+/-1.4$ (median: 9.0 (7.0-10.0)) for the level of activity and $8.7+/-1.3$ (median: 8 (6.0-10.0)) for the residual pain. Seven patients reported no pain and 7 others, only a little one. No difference was found about the different subjective scores according to the complete rupture of the 3 tendons or the rupture of only 1 or 2 tendons.

Twenty-nine isokinetic muscle strength evaluations had been made in the 16 subjects. Seven patients were evaluated once, 5 patients twice and 4 patients 3 times. The large number of isokinetic evaluations enabled us to assess the evolution of the hamstring strength deficits at 4, 12, 24, 36 and 100 months from the injury (Figure 1). Five patients were evaluated at $4.2+/-1.2$ months, 6 at $12.8+/-2.0$ months, 5 at $24.5+/-2.1$ months, 6 at $35.0+/-8.1$ months and 7 at $101.0+/-30.5$ months. Four months after injury, the strength deficit of the injured hamstrings was high, from $40+/-25.0(23-69 \%)$ to $45 \%+/-17.0(20-55 \%)$, both in concentric and eccentric contractions at the angular speed of $60 \% \mathrm{sec}$. Then, the concentric strength deficit decreased until 24 months after injury, to less than $30 \%$. Some patients were nearly symmetrical with a deficit less than $5 \%$. From 3 to 8 years after injury, some other patients had persistent strength deficit, of about $25 \%+/-16.0$ (4 - 46\%). The eccentric strength deficit evolved differently. No improvement was noticed with a mean strength deficit of $40 \%+/-17.0(14-57 \%), 24$ months after injuries. However, values were variable from one patient to another, with a minimal deficit measured at $14 \%$ and a maximal one 


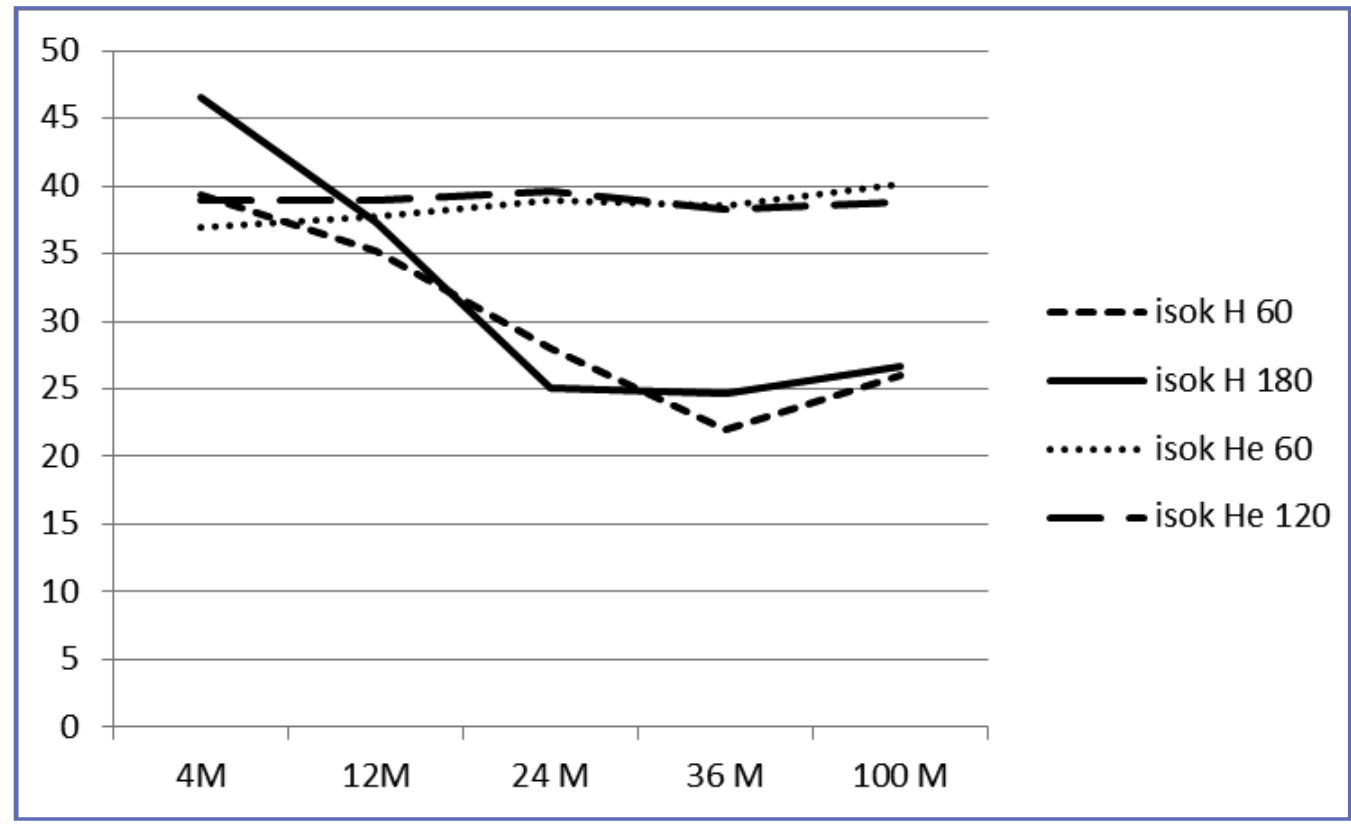

Abbreviations: H: hamstring; e: eccentric mode; 60: angular speed at $60 \% \mathrm{~s}$
Figure 1. Isokinetic concentric and eccentric deficit (\%) from the $4^{\text {th }}$ to $100^{\text {th }}$ month follow-up after proximal hamstring rupture at $57 \%$. No difference was found between patients with a complete rupture of the 3 tendons and those with a rupture of only 1 or 2 tendons.

The results of non-surgical management of proximal hamstring ruptures are usually considered not as good as those after surgery $(11,14,20)$. However, after elimination of bone tears, only few cases of non-operated patients have been described, which is responsible for a lack of evidence to conclude formally in favor of the surgical management (11). We reported 16 new cases of proximal hamstring ruptures including 6 cases of complete rupture of the 3 tendons, which is the largest sport series described to our knowledge. All the patients reported violent pain during traumatism followed by walking disability and difficulty to sit. The treatment consisted in icing, walking with sticks and limitation of the hip flexion according to pain. Return to sport depended on patients' perception. Yet, our results are difficult to compare with precedent studies because of the lack of information previously reported by other authors $(17,20-22,34)$. Indeed, we have been able to compare the type of sports practiced but not the level of practice. Out of the 13 sportive patients clearly described in different articles, 10 used to practice water-skiing, 1 judo, 1 tennis and 1 soccer $(17,21,22,34)$. Half of them could not return to their previous sport, water-skiing in 5 cases and tennis in 1 case $(17,34)$. A complete proximal hamstring rupture of the 3 tendons had been described in all these last 6 cases. Among the 7 other cases with a rupture of 1 or 2 tendons reported in literature $(17,21,22,34)$, all of them were satisfied, 3 went back to sport to the same level of practice and 4 to a lower level. In our series, concerning water-skiing, only one patient $\left(n^{\circ} 1\right)$ out of $3\left(n^{\circ} 1, n^{\circ} 10\right.$ and $\left.n^{\circ} 16\right)$ could return to this sport. Yet, these 3 patients had an incomplete rupture, which is usually considered a better prognosis (17). None of our patients practiced tennis before injury. So, we could not compare our results with those of Gidwani et al., who reported the case of a 20-year patient with a complete proximal rupture (34). This patient practiced tennis at a semi-professional level and refused surgery 2 years after the traumatism. The authors considered subjectively the results as "poor" but did not provide information how this criterion was defined. The impossibility to return to the same level of sport may have been used as a criterion, but going back to tennis to that level is anyway difficult 2 years after a trauma. Conversely, one of our patients $\left(n^{\circ} 12\right)$, who had semimembranosus and biceps femoris ruptures, started practicing tennis after the injury, except for competition. Yet, he was moderately satisfied because he could not run a marathon anymore.

Kurosawa et al. reported that judo in competition was possible after proximal rupture of the hamstrings (21). Though, the isokinetic strength of the hamstrings decreased from 20 to $40 \%$ and occasional cramps were described during jumping and running. Results were better in case of surgery with a decrease of the isokinetic strength of only $20 \%, 7$ months after the surgery and absent at 12 months. 
In our series, 5 cases out of 6 were able to practice soccer again to the same level ( $\mathrm{n}^{\circ} 3,4,6,14$ and 15), 2 patients had a complete rupture of the hamstrings but one of them was not able to play soccer again $\left(\mathrm{n}^{\circ} 9\right)$. Clark et al. (22) described a 26-year patient with a rupture of the biceps femoris and the semimembranosus, while practicing soccer. His muscles were retracted from 2 and $8 \mathrm{~cm}$, respectively. Because of an absence of initial diagnosis, the patient went back to competition 2 months after injury without specific management. Twelve months after injury, the authors found a decrease of isokinetic strength of $12 \%$ on concentric mode and $16 \%$ on eccentric mode, at an angular speed of $90 \%$ s. The 2 patients $\left(\mathrm{n}^{\circ} 7\right.$ and 8 ), who used to practice other pivoting contact sports such as basketball and handball, were not able to return to their previous sports. They had complete muscular rupture of the 3 tendons. Yet, some other patients, even with complete rupture, were able to practice alpine skiing and boxing ( $\mathrm{n}^{\circ} 1,7$ and 13$)$ again.

Cycling was the sport of choice for the most uncomfortable patients. Four patients $(25 \%)$ were capable to return only to this activity, one had a complete rupture. None of them complained about pain. Their subjective scores, UCLA and LEFS, were still not normalized, respectively from 35 to 37 and from 68 to 79 . The absence of difference for all the studied parameters between incomplete and complete ruptures may have been due to the lack of power secondary to the low number of patients. However, Hofmann et al. reported the ability to return to previous sport activities in $70 \%$ of the patients with complete hamstring rupture, but without any detail on the type of sports (19). Recently, Piposar et al. compared patients with complete ( 3 tendons) and incomplete ruptures ( 1 or 2 tendons) with muscle retractions inferior to $2 \mathrm{~cm}$ (14). Fifteen non-operated cases and 10 operated ones were compared on an average period of 35 months after injury. Most of the non-operated patients used to practice water skiing $(n=3)$ and running $(n=3)$ before injury. For 3 others, the sports practiced are unknown. The authors reported no information about the level of sport practice and the return to a sport activity. So, these results could not be compared with our series, in which only 2 patients had a muscle retraction inferior to $2 \mathrm{~cm}$. The LEFS was 64.3, comparable to those of Shambaugh et al. (68.5) (20) and Hofmann et al. (70.2) (19), which is frankly inferior to our results (76.6). Piposar et al. also described impairment for walking, stairs climbing and standing, which was not the case for our patients. Indeed, we reported only 3 patients out of 16 who complained about pain when sitting for more than one hour. One explanation of these results may be the difference of age between the patients, $34+/-12$ years-old in our study and more than 55 years-old in those of Piposar et al. (14), Shambaugh et al. (20) and Hofmann et al.(19).
Our study is original because we assessed isokinetic strength deficit both on concentric and eccentric mode. We found a mean deficit of $25 \%$ on concentric mode 24 months after the injury, which is consistent with previous results reporting deficits from 12 to $40 \%$, even if angular speeds were not always mentioned or not the same as ours (30 to $300^{\circ} / \mathrm{sec}$ ) $(17,21,22)$. Two studies described an average strength deficit of $40 \%$ with an isometric method at 45 and $90^{\circ}$ of knee flexion, which was not comparable with isokinetic assessments. $(19,20)$ Yet, Piposar et al. reported a deficit of only $5 \%$, which may be explained by the fact that they included only patients with a retraction inferior to $2 \mathrm{~cm}$ (14). Isokinetic eccentric deficit remained important $(40 \%)$ and did not improve with time. No comparison was possible with other studies because only one case had been previously evaluated with this mode (22). However, eccentric evaluation seems to be particularly interesting because injuries are usually secondary to an eccentric mechanism or a maximal stretching. Especially since these measures are objective and validated to value strength recovery of the hamstrings after injury in a sportive population $(17,26)$. We reported a more important deficit on eccentric mode than in concentric one (40 vs. $25 \%$ ), which is usual in case of muscular lesions (35). Yet, the persistence of a dissociation between eccentric and concentric modes is arguable, it may be due to a neuromuscular inhibition because of the lack of healing, or/and because of patients' apprehension during isokinetic tests (36). A specific program of rehabilitation with eccentric exercises could have improved the results (37). In our study, in only 3 cases, hamstring strengthening was proposed at the time of isokinetic strength evaluation. Finally, objective isokinetic results were poor, which contrasted with subjective functional ones, which were generally good.

This study has several limits, as it was a retrospective and descriptive one with few patients. However, it remains the most important one in terms of sportive patients. The population was also heterogeneous concerning the types of sports concerned. The rehabilitation programs were not standardized, and the isokinetic assessments were realized at different times after the injury. MRI diagnosis may have provided different results about the type of lesion and muscle retraction compared to those made directly by the surgeon in case of surgical management $(9,38)$. Due to the type of patients' recruitment, there was no therapeutic bias concerning the choice made between surgery or non-surgical management.

\section{CONCLUSIONS}

Proximal ruptures of the hamstrings are rare and their evolution, in case of non-surgical management, is usually considered painful and disabling, especially in case of sport 
practice. Actually this evolution remains not very wellknown because of the few cases reported. The practice of water-skiing seems to be compromised whereas patients can usually go back to soccer playing. In case of complete rupture of the 3 tendons, pivoting contact sports such as handball and basketball remain impossible to play. However, patients' satisfaction is excellent and subjective results are favorable. Isokinetic concentric deficits at $60 \% \mathrm{sec}$ improve until 24 months with a persistent deficit of about $25 \%$ but a major eccentric deficit of about $40 \%$ persists.

\section{REFERENCES}

1. Opar DA, Williams MD, Shield AJ. Hamstring strain injuries: factors that lead to injury and re-injury. Sports Med Auckl NZ 2012;42:209-226.

2. Ahmad CS, Redler LH, Ciccotti MG, Maffulli N, Longo UG, Bradley J. Evaluation and management of hamstring injuries. Am J Sports Med 2013;41:2933-2947.

3. Dauty M, Collon S. Incidence of injuries in French professional soccer players. Int J Sports Med 2011;32:965-969.

4. Ekstrand J, Waldén M, Hägglund M. Hamstring injuries have increased by $4 \%$ annually in men's professional football, since 2001: a 13-year longitudinal analysis of the UEFA Elite Club injury study. Br J Sports Med 2016;50:731-737.

5. Lempainen L, Banke IJ, Johansson K, Brucker PU, Sarimo J, Orava S, Imhoff AB. Clinical principles in the management of hamstring injuries. Knee Surg Sports Traumatol Arthrosc Off J ESSKA 2015;23:2449-2456.

6. Davis KW. Imaging of the hamstrings. Semin Musculoskelet Radiol 2008;12:28-41.

7. Lempainen L, Sarimo J, Heikkilä J, Mattila K, Orava S. Surgical treatment of partial tears of the proximal origin of the hamstring muscles. Br J Sports Med 2006;40:688-691.

8. McGregor C, Ghosh S, Young DA, Maffulli N. Traumatic and overuse injuries of the ischial origin of the hamstrings. Disabil Rehabil 2008;30:1597-1601.

9. Thompson SM, Fung S, Wood DG. The prevalence of proximal hamstring pathology on MRI in the asymptomatic population. Knee Surg Sports Traumatol Arthrosc Off J ESSKA 2017;25:108-111.

10. Bodendorfer BM, Curley AJ, Kotler JA, Ryan JM, Jejurikar NS, Kumar A, Postma WF. Outcomes After Operative and Nonoperative Treatment of Proximal Hamstring Avulsions: A Systematic Review and Meta-analysis. Am J Sports Med 2017;363546517732526.

11. Harris JD, Griesser MJ, Best TM, Ellis TJ. Treatment of proximal hamstring ruptures - a systematic review. Int J Sports Med 2011;32:490-495.

12. Ali K, Leland JM. Hamstring strains and tears in the athlete. Clin Sports Med 2012;31:263-272.

13. Lempainen L, Banke IJ, Johansson K, Brucker PU, Sarimo J, Orava S, Imhoff AB. Clinical principles in the management of hamstring injuries. Knee Surg Sports Traumatol Arthrosc Off J ESSKA 2015;23:2449-2456.

14. Piposar JR, Vinod AV, Olsen JR, Lacerte E, Miller SL. HighGrade Partial and Retracted $(<2 \mathrm{~cm})$ Proximal Hamstring
Studies with larger populations comparing surgical versus non-surgical management should be performed to better determine the place of these different treatments, considering the complete or incomplete nature of the muscular rupture and the desire to return to a sport such as water-skiing, soccer, basketball or handball.

\section{Conflict of interests}

The Authors declare that they have no conflict of interests
Ruptures: Nonsurgical Treatment Revisited. Orthop J Sports Med 2017;5:2325967117692507.

15. Subbu R, Benjamin-Laing H, Haddad F. Timing of surgery for complete proximal hamstring avulsion injuries: successful clinical outcomes at 6 weeks, 6 months, and after 6 months of injury. Am J Sports Med 2015;43:385-391.

16. Skaara HE, Moksnes H, Frihagen F, Stuge B. Self-reported and performance-based functional outcomes after surgical repair of proximal hamstring avulsions. Am J Sports Med 2013;41:2577-2584.

17. Sallay PI, Friedman RL, Coogan PG, Garrett WE. Hamstring muscle injuries among water skiers. Functional outcome and prevention. Am J Sports Med 1996;24:130-136.

18. Wood DG, Packham I, Trikha SP, Linklater J. Avulsion of the proximal hamstring origin. J Bone Joint Surg Am 2008;90:2365-2374.

19. Hofmann KJ, Paggi A, Connors D, Miller SL. Complete Avulsion of the Proximal Hamstring Insertion: Functional Outcomes After Nonsurgical Treatment. J Bone Joint Surg Am 2014;96:1022-1025.

20. Shambaugh BC, Olsen JR, Lacerte E, Kellum E, Miller SL. A Comparison of Nonoperative and Operative Treatment of Complete Proximal Hamstring Ruptures. Orthop J Sports Med 2017;5:.

21. Kurosawa H, Nakasita K, Nakasita H, Sasaki S, Takeda S. Complete avulsion of the hamstring tendons from the ischial tuberosity. A report of two cases sustained in judo. Br J Sports Med 1996;30:72-74.

22. Clark BB, Jaffe D, Henn RF, Lovering RM. Evaluation and imaging of an untreated grade III hamstring tear: a case report. Clin Orthop 2011;469:3248-3252.

23. Askling CM, Koulouris G, Saartok T, Werner S, Best TM. Total proximal hamstring ruptures: clinical and MRI aspects including guidelines for postoperative rehabilitation. Knee Surg Sports Traumatol Arthrosc Off J ESSKA 2013;21:515533.

24. Startzman AN, Fowler O, Carreira D. Proximal Hamstring Tendinosis and Partial Ruptures. Orthopedics 2017;40:e574e582.

25. Maffulli N, Oliva F, Frizziero A, Nanni G, Barazzuol M, Via AG, Ramponi C, Brancaccio P, Lisitano G, Rizzo D, Freschi M, Galletti S, Melegati G, Pasta G, Testa V, Valent A, Del Buono A. ISMuLT Guidelines for muscle injuries. Muscles Ligaments Tendons J 2013;3:241-249. 
26. Dauty M, Menu P, Fouasson-Chailloux A. Cutoffs of isokinetic strength ratio and hamstring strain prediction in professional soccer players. Scand J Med Sci Sports 2017;

27. Chakravarthy J, Ramisetty N, Pimpalnerkar A, Mohtadi N. Surgical repair of complete proximal hamstring tendon ruptures in water skiers and bull riders: a report of four cases and review of the literature. Br J Sports Med 2005;39:569572.

28. Impellizzeri FM, Bizzini M, Rampinini E, Cereda F, Maffiuletti NA. Reliability of isokinetic strength imbalance ratios measured using the Cybex NORM dynamometer. Clin Physiol Funct Imaging 2008;28:113-119.

29. Tegner Y, Lysholm J. Rating systems in the evaluation of knee ligament injuries. Clin Orthop 1985;43-49.

30. Calistri A, Di Martino L, Gurzì MD, Bove M, De Smet K, Villani C. Italian version of University of California at Los Angeles (UCLA) Activity Score: cross-cultural adaptation. J Arthroplasty 2014;29:1733-1735.

31. Binkley JM, Stratford PW, Lott SA, Riddle DL. The Lower Extremity Functional Scale (LEFS): scale development, measurement properties, and clinical application. North American Orthopaedic Rehabilitation Research Network. Phys Ther 1999;79:371-383.
32. Lefevre N, Bohu Y, Naouri JF, Klouche S, Herman S. Returning to sports after surgical repair of acute proximal hamstring ruptures. Knee Surg Sports Traumatol Arthrosc Off J ESSKA 2013;21:534-539.

33. Padulo J, Oliva F, Frizziero A, Maffulli N. Muscles, Ligaments and Tendons Journal - Basic principles and recommendations in clinical and field Science Research: 2018 update. MLTJ 2018; 8(3): $305-307$.

34. Gidwani S, Bircher MD. Avulsion injuries of the hamstring origin - a series of 12 patients and management algorithm. Ann R Coll Surg Engl 2007;89:394-399.

35. Tol JL, Hamilton B, Eirale C, Muxart P, Jacobsen P, Whiteley $\mathrm{R}$. At return to play following hamstring injury the majority of professional football players have residual isokinetic deficits. Br J Sports Med 2014;48:1364-1369.

36. Dueweke JJ, Awan TM, Mendias CL. Regeneration of Skeletal Muscle After Eccentric Injury. J Sport Rehabil 2017;26:171-179.

37. Cushman D, Rho ME. Conservative Treatment of Subacute Proximal Hamstring Tendinopathy Using Eccentric Exercises Performed With a Treadmill: A Case Report. J Orthop Sports Phys Ther 2015;45:557-562.

38. Cohen S, Bradley J. Acute proximal hamstring rupture. J Am Acad Orthop Surg 2007;15:350-355. 